The whole staff directs the laboratory; and over and above these are the two professors of physiological and agricultural chemistry, who conduct their own laboratories.

In Physics, Professor Weber and his assistants, Professors Listing and Kohlrausch, conduct an excellent physical laboratory, and lecture on the several branches of physics-systematic physics, optics, electricity, \&c., light and heat, meteorology. Professor Ulrich treats of hydrostatics and hydraulics.

In Natural History, Professor Keferstein lectures on comparative anatomy, and performs zootomical demonstrations in the Zoological Museum during eight hours weekly to the students; for four hours weekly the Museum is open to the public, when the same Professor is present to conduct demonstrations. Two professors lecture on Botany (each six houtrs weekly), and combine with their lectures excursions and demonstrations in the Botanical Garden ; there is also a third assistant professor. Professors Sartorius Von Waltershansen and Von Seebach lecture each four or five hours weekly on Mineralogy and Geology, and conduct practical demonstrations in the Museums.

In Heidelberg, as in Berlin and Göttingen, and in some respects even in a more perfect measure, large provision is made for the study of physical science. The Physical Laboratory, conducted by Professor Kirchhoff, is very successful. Once weekly Professor Kirchhoff lectures, with experiments, on a given subject; in the following week each student in the laboratory goes. through the experiments for himself, and in this consists the essence of the course. Students can also prosecute independent research for several days in the week.

'The Chemical School of Heidelberg has always been a celebrated one, and since the appointment of Bunsen to the university its renown has greatly increased. In no other European laboratory, with the single exception of that of Liebig at Giessen, have so many promising scientific chemists been trained, and this has been wholly due to the untiring interest shown in each student by the illustrious Professor, who, devoted heart and soul to his science, imparts to his students a portion of that interest in, and zeal for, original investigation, which are the real marks of a scientific spirit. Many of the chemical students at Heidelberg come, as with us, to study the science for the sake of its subsequent applications to manufactures, medicine, or pharmacy (for all the German druggists and pharmaceutical chemists are wisely compelled to attend a regular university course), but many, probably a large fraction of the number, study the science for its own sake, most of these students intending to qualify themselves for the higher posts of scientific instruction in various countries. Amongst the companions of those who studied at Heidelberg with the writer were men who are now making rising reputations in most of the German universities, or in the various institutions of France, Russia, Portugal, Great Britain, and America.

The Physiological Laboratory, conducted by the celebrated philosopher Helmholtz, is a novel and important feature in the Science Department in Heidelberg. A handsome and spacious building has recently been erected for the use of the Professors of Physics and Physiology. This embraces lecture-rooms, laboratories, rooms for apparatus and instruments, and for conducting special scientific investigations, besides dwelling-houses for the professors and their families.

In another article I propose to inquire more closely into the cost of establishing and working the Science Department of the German universities.

HENRY E. ROSCOE

\section{A POINT IN MUSCULAR PHYSICS}

SOME Physiologists abound in statements touching the correlation of forces in living things, and are very fond of repeating the old parallel between a muscle and a steam-engine. We have no desire to deny the aptness of the illustration, but it is as well to bear in mind that, in actual point of fact, the exact correlation of heat and mechanical force has not, as far as muscle is concerned, yet been made fully out. The point of failure is this-suppose we have two muscles: let one muscle when it contracts have to pull against a weight and so produce a decided mechanical effect; let the other muscle have no such weight to pull against, and so in contracting produce no mechanical effect (the trifling weight of the muscle itself we may disregard). According to the doctrine of the correlation of forces, the heat given out in the first case ought to be less than that given out in the second, by reason of the total force produced by the combustion of the muscle going out partly as mechanical force instead of wholly as heat. We suppose of course that exactly same amount of contraction takes place in both cases, and indeed that the muscles are perfectly identical in circumstances, except so far as their load is concerned. Heidenhain some few years ago, however, found out that there was, strange to say, more heat given out in the first case. He also discovered the reason of it, which is that when a muscle is put on the stretch, as, for instance, when a muscle has in contracting to pull against a weight, all the chenical changes in the muscle are augmented, and that roughly in proportion to the amount of strain.

This observation by Heidenhain seems to us one of very far-reaching and often-recurring importance, though apparently it has hardly as yet gained the attention it deserves. At all events it put a stop for a while to any satisfactory settlement of the question we are considering. Quite recently, however, Fick has devised an experiment which seemed to him to avoid the difficulty that had discomfited Heidenhain. The gist of it is simply this. He has two muscles in every way treated alike except in the following point. One muscle he allows to pull a weight up by the force of its contraction, and then lets the weight, when the contraction has passed over, pull the muscle down again. The other muscle pulls up the same weight in the same way, but at the moment that the contraction is at its maximum the weight is slipped off. The muscle then by virtue of its elasticity returns to the length natural to it when unloaded; directly it has reached this point the weight is slipped on again, and the muscle is again ready for a contraction.

It is obvious that in the first case the muscle does no actual work at all; after the contraction the weight undoes what the contraction did. In the second case, on the other hand, the weight is lifted up to a certain point and left there; real work is done.

Such being the case, the temperature of the first muscle ought to rise higher than the second; and when each muscle has been made to contract a good many times this rise ought to be appreciable. Fick finds in fact that it is so. And so we seem here to have what we desired; for both muscles during contraction are subject to the same strain; and hence Heidenhain's objection is obviated. 
That cautious inquirer is not, however, yet satisfied. He asks " if during contraction an increase of strain produces an increase in the total chemical processes (metamorphosis) of the muscle, are we to think that the effect of the strain ceases to be felt immediately the contraction is finished, and is not carried on into the period of relaxation?

And moreover, putting the matter to an experimental inquiry, he finds, as a matter of fact, that when two muscles are treated as in Fick's experiment, one strained at all times, and the other strained only during contraction, the amount of chemical change taking place in the first, as evidenced by the generation of acid, is distinctly larger than in the second. So there the question remains for the present.

\section{THE PROZECTED CHANNEL RAILWAYS}

THE first question to be asked about a railway between England and France would be properly one upon its importance, and on the value of such a railway to the social and commercial interests of the two countries.

Let us consider the present situation and the circumstances which would affect, favourably or otherwise, a Channel Railway.

A sheet of water, impassable at all times to the bulk of a people, although a highway of their sailors, is a most effectual barrier between two countries. Free intercourse is checked; the exchange of ideas and thought Jimited to a small class of traders and travellers, not to mention the learned, who in all countries form but a minority of the people.

Two nations so situated are generally cold towards each other, and in time materially differ in their mode of living, in their ideas, habits, and in their institutions. A free intercourse need not necessarily obliterate the peculiarities of different races; but it has always been an effective means of moderating prejudices.

To attempt a description of the numerous and subtle ways by fwhich the mind of populations may be taken hold of-and even be guided-would be beyond our present object; but as a means of self-education and consequent civilisation, there could not be a more powerful instrument than railways, because they offer the readiest, most convenient, and the cheapest means of communication between one individual and another.

Half-a-century ago the bulk of a nation was enclosed within its own walls; only a small minority could afford to travel and to observe, to exchange and to induce thought. That in which all schools must necessarily fail, or at least can succeed but indifferently-viz., the education of the million-railways are accomplishing with extraordinary rapidity; their civilising influence is constantly at work: they cover England more than any other country, and accordingly England derives all the benefit which that institution may confer on a people. Railways are also in a great measure covering France, Belgium, Germany, \&c. ; but there is an essential difference between the effect which they may produce in England and on the Continent. In England they interchange and mix the ideas and habits principally of the Anglo-Saxon race, some twenty odd millions; on the Continent they cause to mingle several great nations of different race: certainly more than sixty millions are there under the operation of railways as an institution.

The civilising influence of railways is, in England, accordingly confined to one groove - one main AngloSaxon line-and the effect on the English people cannot but remain elementary : on the Continent, however, their civilising power derives its material from several distinct and essentially different sources, viz., the Teutonic and Gallic races, and some others of minor consequence, the material of which, interwoven and allied by the affinity of thought, forms a compound of a different nature and character, differing as much as compounds differ from their elements.

That these causes have been in operation in the manner indicated, we may easily trace in the relative progress made within one generation in England and on the Continent. When railways were in their infancy; England was, in her institutions and industry, much ahcad of any country. Railways have improved the condition of every people, but has the improvement not been very much greater on the Continent? It may be urged, that there was more room for improvement in those countries: that may be so, but this would not affect the case, for there was and is room enough for improvement at home.

Within one generation railways have produced wonderful revolutions on the Continent. The despotic governments of several great nations have given way to truly liberal institutions; continental industry rivals already that of England. And how was all that brought about? The immediate causes of these changes may seem innumerable; and yet, there is only one great cause at the bottom of all this change, viz. enlightenment of the people; and we claim a large share of this result for the institution of railways.

If, then, the combination of thought originating from different sources has so much advanced and civilised the Continent, what would be the effect upon England if a railway could suddenly bring the bulk of her people in close contact with the continental nations? A more complex, a higher compound would be formed, and what the ultimate effect of this change might be the future alone could tell; all that can be said with certainty at present is this, that enlightemment must follow in a potential form. Excursion trains would take the million to and from either country; excursions to and from Paris would be made with the same convenience and comfort as now between Manchester, Liverpool, London, and other large towns; in short, the social effect of the change would be immense; and how would it affect the commercial interests? Enough has already been said to show that a channel railway in good working condition would accomplish wonders, and it may be easily perceived that, though all will be gainers by the change, England would gain the most.

This being so, then, the next point is to analyse the different projects which have been proposed for bringing the result about. Among these, the Bridge scheme has naturally received considerable public attention. To the non-professional mind it appears a plausible proposition, and enough support has been given to its promoters to enable them to promise wonders.

We have no definite plan of the proposed bridge, but we have a Channel Bridge Company; we have not even a definite outline of the main engineering features, but we have the assurance of the success of a model which, in the opinion 